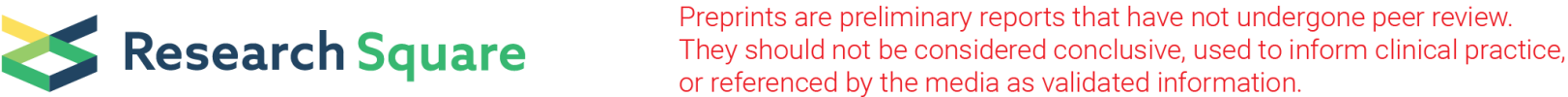

\section{Development of an Efficient and Stable Transformation System for Aspergillus Oryzae Based on the pyrG Gene}

\section{Caixia Zhou}

Sichuan Agricultural University

\section{Yujun Wan}

Sichuan food fermentation industry research and design institute

\section{Huipeng Yao}

Sichuan Agricultural University

\section{Hui Chen}

Sichuan Agricultural University

\section{Yirong Xiao}

Sichuan Agricultural University Hospital

\section{Zizhong Tang ( $D$ 14126@sicau.edu.cn )}

https://orcid.org/0000-0002-4197-9265

\section{Zhi Shan}

Sichuan Agricultural University

\section{Tongliang Bu}

Sichuan Agricultural University

Hong Chen

Sichuan Agricultural University

\section{Gang Wang}

Sichuan food fermentation industry research and design institute

\section{Research}

Keywords: Aspergillus oryzae, uridine/uracil auxotrophic, expression vector, PEG-CaCl2-mediated transformation

Posted Date: May 5th, 2020

DOI: https://doi.org/10.21203/rs.3.rs-26135/v1

License: (c) (1) This work is licensed under a Creative Commons Attribution 4.0 International License. Read Full License 


\section{Abstract}

Background Aspergillus oryzae is an ideal host for expressing heterologous and homologous genes. An efficient and stable transformation system is the key to the successful expression of the gene of interest in A. oryzae.

Results To improve the expression efficiency of the gene of interest in A. oryzae, we constructed the uridine/uracil auxotrophic strains $A$. oryzae RIB40 $\triangle p y r G$ by Ultraviolet (UV) mutagenesis of pyrG gene deletion which would be used as a host for further transformation. In addition, a novel and efficient expression vector $\mathrm{pBC}$-hygro. 4 was constructed, including the $p y r G$ cassette gene, His-Tag, amy $B$ promoter and terminator,and green fluorescent protein GFP marker. pBC-hygro.4 transformed A. oryzae RIB40 $\Delta$ pyrG efficiently via the PEG-CaCl ${ }_{2}$-mediated transformation method, and the stability of pBChygro.4 was tested by detecting the expression of the GFP reporter gene. Through phenotyping and sequencing verification, we successfully obtained a uridine/uracil auxotrophic strains $A$. oryzae RIB40 $\Delta p y r G$. At the same time, the developed vectors are fully functional for heterologous expression of the GFP fluorescent proteins in the A. oryzae RIB40 $\Delta$ pyrG.

Conclusion Our work provides a new method that can be applied to other filamentous fungi to develop similar fungal transformation systems based on auxotrophic/nutritional markers for food-grade recombination applications.

\section{Background}

Aspergillus oryzae is an important industrial microorganism has been widely used in the fermentation industry and food processing ${ }^{[1-3]}$. It was recognized as a safe strain by the US Food and Drug Administration (FDA) ${ }^{[4,5]}$. A. oryzae is often used as an ideal host cell for heterologous gene expression, protein secretion and metabolite production ${ }^{[6]}$. Because it has the ability to secrete the target protein into the culture medium, which makes the purification process of products become simpler and more efficient ${ }^{[7,8]}$.

The selection of appropriate selectable markers is necessary for the transformation process, which can make the screening of positive transformants more effective. Studies have shown that $A$. oryzae is to be inherently resistant to most common antibiotics such as hygromycin B, geneticin(G418) and bleomycin ${ }^{[9}$, 10]. Thus, it is difficult to obtain transformants by selection with commonly used antibiotics. Therefore, it is necessary to develop a transformation system based on nutritional markers. The pyrG gene, ending orotidine-5'-monophosphate(OMP) decarboxylase participates in uridine biosynthesis and is also a target for the antimetabolite 5-fluoroorotic acid(5-FOA), which is as a selective marker and its auxotrophic strain as a genetic transformation host ${ }^{[11-14]}$. OMP decarboxylase is able to convert the non-toxic 5 -fluoroorotic acid (5-FOA) into the toxic product as 5-fluorouracil, which consequently inhibits the growth of wild-type fungi ${ }^{[15,16]}$. However, the corresponding pyrG mutants can grow normally on the medium containing 5 - 
FOA. Therefore, 5-FOA was often used to identify uridine/uracil auxotrophic mutant strains in different filamentous fungi ${ }^{[17]}$.

Currently the most commonly used methods for filamentous fungi transformation including PEG (polyethylene glycol)-mediated protoplast transformation(PMPT) and Agrobacterium tumefaciensmediated transformation (ATMT $)^{[18,19]}$. In comparison with the ATMT method, PEG-CaCl${ }_{2}$-mediated transformation has some disadvantages, such as low transformation efficiency, difficulty in obtaining high concentrations of viable protoplasts, high percentages of transient transformants ${ }^{[20,21]}$. However, due to its simplicity in technical operation and equipment required, the PEG- $\mathrm{CaCl}_{2}$-mediated transformation remains the most commonly used method to conduct transformation in filamentous fungi[22].

In recent years, $A$. oryzae as an expression host for heterologous gene expression has attracted a lot of interest, so the construction of highly efficient $A$. oryzae expression vectors is particularly important. Many previous studies have shown that vectors constructed with plasmid pBC-hygro as the backbone can be effectively transformed in various filamentous fungi, such as Aspergillus fumigates ${ }^{[23]}$, Aspergillus sydowii $^{[24]}$, Thermomyces lanuginosus ${ }^{[25]}$, and Podospora anserine ${ }^{[26]}$. Taka-amylase (amyB) promoters and terminators were widely used for the efficient expression of many genes. In this study, a novel vectors pBC-hygro.4 carrying A. oryzae pyrG marker was constructed for the transformation of uridine/uracil auxotrophic $A$. oryzae via an adapted PEG-CaCl ${ }_{2}$-mediated transformation method. The construction of the $A$. oryzae expression system will lay the foundation for the successful expression of foreign genes in A. oryzae and provide a new method that can be applied to other filamentous fungi to develop similar fungal transformation systems based on auxotrophic / nutrition markers.

\section{Results}

\section{Determination of 5-FOA minimum use concentration}

The resistance of wild-type $A$. oryzae RIB40 to different concentrations 5-FOA was analyzed. To isolate a selection agent suitable for pyrG deletion mutants screening, the growth of wild-type $A$. oryzae RIB40 on CD plates containing 5-FOA at different concentrations $(0.5,0.75,1.0,1.25,1.5 \mathrm{mg} / \mathrm{mL})$ was observed. The result shown that $1.0 \mathrm{mg} / \mathrm{mL} 5$-FOA inhibited the growth of wild-type $A$. oryzae RIB40 for the longest time (Fig. 1). Therefore, $1.0 \mathrm{mg} / \mathrm{mL}$ 5-FOA was chosen as the selection agent for $p y r G$ deletion mutants screening.

\section{Screening and characterization of pyrG deletion mutants}

We obtained many mutant strains by UV mutagenesis. After preliminary screening through 5-FOA plates, we succeeded to gain five resistant strains that can grow on 5-FOA plates, named P1-P5. Then, mutant strains to resistant to 5-FOA were transferred simultaneously to the CD, CD + Uri/Ura and CD + Uri/Ura + 5- 
FOA (1 mg/mL) to examine their growth (Fig. 2). The result showed that the wild type was unable to grow on CD + Uri/Ura + 5-FOA plates and grew well on CD, CD + Uri/Ura. However, the pyrG deletion mutants P1$\mathrm{P} 5$ were unable to grow on $\mathrm{CD}$ plates without uridine and uracil and grew well on $C D+$ Uri/Ura, $C D+$ Uri/Ura + 5-FOA plates (Fig. 2), indicating that strains P1-P5 were uridine auxotrophs. These uridine auxotrophs were detected by further PCR to identify pyrG deletion.

For the five uridine auxotrophs, the predicted $1.8 \mathrm{~kb}$ pyrG cassette fragments (Fig. 3) were amplified from the genomic DNA of the mutants using the primer pair pyrGF/pyrGR. The P1-P5 strain amplified a specific band of about $1.8 \mathrm{~kb}$, which was consistent with the wild-type A. oryzae RIB40 pyrG cassette sequence size. We selected strain P1 and purified its PCR product by gel recovery kit and sent it to invitrogen for sequencing. The sequencing results were compared with the wild type $A$. oryzae RIB40 pyrG cassette sequence, nucleotide sequencing revealed that strain containing pyrG mutations were successfully obtained. Strain P1 contain $1 \mathrm{bp}$ deletion and $1 \mathrm{bp}$ insertion at the target sequence of the $p y r G$ gene(Fig. 4). These mutations all cause frameshifts, which suggests that the $p g r G$ gene does not function in the strains.

\section{Dna Manipulation And Plasmid Construction}

First, we verified the resistance of $A$. oryzae RIB40 $\Delta p y r G$ to hygromycin $\mathrm{B}$. The spore suspension was cultivated in $C D$ medium containing $0,0.5,1.0,1.5,2.0 \mathrm{mg} / \mathrm{mL}$ for 4 days at $28^{\circ} \mathrm{C}$. We found that hygromycin $\mathrm{B}$ has no inhibitory effect on $A$. oryzae RIB40 $\triangle p y r G$, so we need to delete the hygromycin $\mathrm{B}$ gene sequence. Analysis of the plasmid pBC-Hygro's sequence revealed that it contained three NdeI restriction sites, which were located at sequences 3861 bp, 4539 bp, and 4991 bp, and the sites at $4539 \mathrm{bp}$ and $4991 \mathrm{bp}$ were located in hygromycin B gene sequence. Therefore, we can choose to delete the $\mathrm{Nde}$ I restriction sites at $3861 \mathrm{bp}$ and use $\mathrm{Ndel}$ digestion to destroy the hygromycin B resistance gene so that it loses its activity. We use site-directed mutagenesis to mutate base $\mathrm{C}$ at $3861 \mathrm{bp}$ to base $\mathrm{T}$. For specific methods, refer to the site-directed mutation kit. Design mutant primers TbndeF/TbndeR and sequencing primers TucxF/TucxR. The primer sequences are shown in Table 2. 
Table 2

Primers and their sequences used for PCR in this study.

\begin{tabular}{|ll|}
\hline Primers & sequences $\left(\mathbf{5}^{\prime}\right.$ - $^{\prime}$ ) \\
\hline pyrGF & GGGAATTCATGCGAAGGTAAGTGCTTCT \\
\hline pyrGR & GGACTAGTTGGCTAGGCTCTGACTCG \\
\hline TbndeF & TACAGAATAGCGCGCGCATCTATATGTTAGT \\
\hline TbndeR & AGATGCGCGCGCTATTCTGTAGAGCTCTGGG \\
\hline TucxF & GTTGGAGGCCCTGTCTCCG \\
\hline TucxR & TTCTGAGTGTTCAGGATTGAAGCT \\
\hline pyrgbdhF & GGAATTCCATATGTGAAAGACTGCTGCAAAGCC \\
\hline pyrgbdhR & GGAATTCCATATGAAGCAGTCGTACATACATGG \\
\hline GFPf & CACTAGCTAGCATGAGTAAAGGAGAAGAAC \\
\hline GFPr & CCCAAGCTTTTATTTGTATAGTTCATCCATG \\
\hline amybtF & ATAAGAATGCGGCCGCGGGTGGAGAGTATATG \\
\hline amybtR & ATAAGAATGCGGCCGCAATTCTTGAGGACCATTAC \\
\hline
\end{tabular}

Mutagenesis reactions were performed in a $50 \mu \mathrm{L}$ volume containing $10 \mu \mathrm{L} 5 \times$ FastAlteration Buffer, $2 \mu \mathrm{L}$ template plasmid DNA, $2 \mu \mathrm{L}$ of each TbndeF/TbndeR, $1 \mu \mathrm{L}$ FastAlteration DNA Polymerase, and $33 \mu \mathrm{L}$ RNase-Free $\mathrm{ddH}_{2} \mathrm{O}$. Reactions were thermal cycled: $95^{\circ} \mathrm{C}$ for $2 \mathrm{~min}$, followed by 18 cycles of $94^{\circ} \mathrm{C}$ for 20 $\mathrm{sec}, 60^{\circ} \mathrm{C}$ for $10 \mathrm{sec}$, and $68^{\circ} \mathrm{C}$ for $210 \mathrm{sec}$, then a final incubation of $68^{\circ} \mathrm{C}$ for $5 \mathrm{~min}$. Reactions were cooled on ice and digested with 5 units of $D p n I$ for $1 \mathrm{~h}$ at $37^{\circ} \mathrm{C}$ to cleave methylated and hemimethylated parental DNA, but not the newly synthesized mutant DNA molecules. The mutant plasmid was verified by DNA-sequencing using the sequencing primers TucxF/TucxR (Table 2), Name the correct mutant plasmid pBC-Hygro.1.

The primers used in this study are listed in Table 2. The novel protein expression vector pBC-Hygro.4 consisted of There fragments (One, Two, Three). Fragment One, the pyrG cassette as the auxotrophic marker was amplified from the genome of the wild-type $A$. oryzae RIB40 strain using primers pyrgbdhF/pyrgbdhR. Fragment Two includes the promoter amy $B$ amplified from wild-type $A$. oryzae RIB40 strain with primers amybF/amybR, and a green fluorescent protein GFP marker amplified from plasmid pHBT-GFP-NOS using primers GFPf/GFPr, which is fused by SOE-PCR. The fused fragment amgfp was inserted into pET30b at the restriction enzyme sites Sal I/Xho I, resulting in the pET-amgfp expression vector. Meanwhile, the amgfp + His-Tag amplified from plasmid pET-amgfp with primers amygfpHTf/amygfpHTr. Fragment Three includes terminator amyB amplified from the genome of the wild-type A. oryzae RIB40 strain with primers amybtF/ amybtR. All of the three DNA fragments were 
ligated with ClonExpress MultiS One Step Cloning Kit and $\mathrm{T}_{4} \mathrm{DNA}$ ligase to generate $\mathrm{pBC}$-Hygro.4. All the constructed plasmids were confirmed by PCR and DNA-sequencing.

\section{A. oryzae RIB40 $\Delta$ pyrG protoplast preparation, transformation}

A. oryzae RIB40 $\Delta$ pyrG protoplasts were prepared with reference to the BestBio company Filamentous Fungal Protoplast Preparation Kit. The transformation was performed by the $\mathrm{PEG}-\mathrm{CaCl}_{2}$ transformation method as described by Unkles et al ${ }^{[49]}$.

\section{GFP reporter gene expression}

DNA of the plasmid pBC-Hygro.4 $20 \mu \mathrm{L}$ was mixed with $200 \mu \mathrm{L}$ of protoplasts. The transformation was performed by the $\mathrm{PEG}-\mathrm{CaCl}_{2}$ transformation method as mentioned above. The transformants were verified by PCR with the primers amygfpHTf and amygfpHTr. Then, the positive colony was cultured in fermentation medium at $30^{\circ} \mathrm{C}$ for $72 \mathrm{~h}$ to obtain the positive recombinants. The fermentation broth was transferred to a glass slide and observed with a fluorescence microscope. The exposure time was $0.1 \mathrm{~s}$, the excitation light was $488 \mathrm{~nm}$, and the emission light was $597 \mathrm{~nm}$.

\section{Discussion}

It is well-know that $A$. oryzae is an excellent host used to express homologous and heterologous proteins ${ }^{[29]}$. In recent years, it has been widely used in the production of heterologous proteins and has received increasing attention ${ }^{[8]}$. A. oryzae has many advantages as an expression host, such as a strong ability to produce and secrete proteins, and strong post-translational modification ${ }^{[30,31]}$. Therefore, it is important to develop an effective $A$. oryzae transformation system.

There are three kinds of selective markers commonly used in filamentous fungi transformation: auxotrophic complementary genes, drug resistance genes, and genes that can make the host use some unusual carbon or nitrogen sources ${ }^{[22]}$. The transformation systems, which were based on drug resistance genes as main selectable markers have the advantage of the availability of a wild type strain as a host and easy operation ${ }^{[32]}$. During the transformation of filamentous fungi, most choose to use some genes encoding resistance as selection markers, such as hygromycin and phleomycin ${ }^{[33,34]}$. However, studies have shown that $A$. oryzae is insensitive to most the common antibiotics such as hygromycin $B$, geneticin(G418) and bleomycin ${ }^{[9,10]}$. Moreover, in this study, we found that hygromycin $B$ cannot inhibit $A$. oryzae RIB $40 \triangle p y r G$ growth. Compared with the other systems, the auxotrophic complementary genetic transformation system has proved to be more efficient. 
As a result, transformation systems for $A$. oryzae have been developed mainly based on nutritional markers. The pyrG gene, ending orotidine-5'-monophosphate (OMP) decarboxylase participates in uridine biosynthesis but is also a target for the antimetabolite 5-fluoroorotic acid (5- FOA). Thus, pyrG genes in filamentous fungi have been widely used as nutritional/auxotrophic markers for fungal transformation ${ }^{[35]}$. In the present study, the pyrG deletion mutants were successfully obtained by UV mutagenesis. Mutants were selected with 5-FOA, which selectively allows the growth of pyrG deletion strains. As expected, these strains exhibited uridine/uracil auxotrophy and resistance to 5-FOA. Meanwhile, the deletion of the $p y r G$ gene was further confirmed by genome PCR and DNA sequencing. UV mutagenesis is a simple method, we successfully obtained $A$. oryzae RIB $40 \triangle p y r G$ through this method. However, mutations induced by UV mutagenesis also have disadvantages such as unstable and uncertain direction of mutation ${ }^{[36]}$.

With the widespread use of $A$. oryzae in the expression of heterologous proteins, it is particularly important to construct a safe and efficient expression vector for A.oryzae. In this study, a novel expression-stable vectors pBC-hygro. 4 was constructed and stably expressed in $A$. oryzae RIB $40 \Delta p y r G$ strain. These vectors possess the changeable components including the pyrG cassette gene, His-Tag, amyB promoter, and terminator amyB. The $p y r G$ transformation system has a great advantage of a lower false-positive background in transformation experiments (Hao et al. 2008). Promoters and terminators are important expression elements that play a key role in the efficient expression of genes. Studies have shown that different promoters have different efficiency, and strong promoters can effectively improve the stability and transcription level of $m \mathrm{mNA}^{[37]}$. There are some strong promoters for gene expression in $A$. oryzae, such as $a m y B, m e l O, g l a A, g p d A$ and tef $7^{[38-41]}$. Based on previous reports, the amy $B$ promoter is much better than the gpdA promoter in the regulation of gene expression in $A$. oryzae ${ }^{[42]}$. Therefore, in this study, the amy $B$ promoter and terminator have been considered as the strongest elements in the construction of expression vectors for $A$. oryzae to produce homologous and heterologous proteins. GFP is the most common fluorescent proteins used for tagging filamentous fungi, which can as a reporter to test the stability of pBC-Hygro. 4 in $A$. oryzae RIB $40 \Delta p y r G^{[43]}$. In the present study, we could directly detect the expression of the GFP reporter gene by recombinant $A$. oryzae RIB $40 \Delta p y r G$ cultures presented remarkable green fluorescence in the mycelia. These results suggest that the gfp gene was successfully expressed in A. oryzae RIB $40 \Delta p y r G$, which demonstrated that vector pBC-Hygro.4 can be used for the expression of foreign genes in $A$. oryzae.

In addition, $A$. oryzae has the ability to express large amounts of various enzymes, such as a-amylase ${ }^{[44]}$, glucoamylase ${ }^{[45,46]}$, and a-glucosidase ${ }^{[47]}$. Compared with eukaryotic expression systems based on Pichia pastoris and Saccharomyces cerevisiae, A. oryzae expression has higher safety, so it can be widely used in food industry. Therefore, the $A$. oryzae expression system constructed in this study provides a prerequisite for the expression of more foreign genes in the future. In future studies we can use this system to express more heterologous and homologous proteins, such as xylanase, cellulose Enzymes, proteases, etc. 


\section{Conclusions}

In summary, in the present study, we successfully obtained $A$. oryzae RIB $40 \Delta p y r G$ strain by UV mutagenesis which would be used as a host for further transformation. In addition, we have constructed a new type of safe and efficient $A$. oryzae expression vector, which can stably express in A. oryzae RIB 40 $\Delta$ pyrG. This will be a new method that can be applied to other filamentous fungi to develop similar fungal transformation systems based on auxotrophic/nutritional markers for food-grade recombination applications.

\section{Materials And Methods}

\section{Bacterial strains and plasmids}

All bacterial strains and plasmids used in this work are listed in Table 1. A. oryzae RIB40, a wild-type strain, was stored previously in our laboratory. Escherichia coli DH5a was used for routine plasmid construction and maintenance, which grown in Luria-Bertani (LB) medium.

Table 1

Strains and plasmids used in this study.

\begin{tabular}{|c|c|c|}
\hline $\begin{array}{l}\text { Strains or } \\
\text { plasmids }\end{array}$ & Description & Source \\
\hline \multicolumn{3}{|l|}{ Strains } \\
\hline A. oryzae RIB40 & The wild-type strain & $\begin{array}{l}\text { This } \\
\text { lab }\end{array}$ \\
\hline $\begin{array}{l}\text { A. oryzae } \\
\text { RIB40 } \Delta p y r G\end{array}$ & The pyrG deletion mutant generated from the RIB40 strain & $\begin{array}{l}\text { This } \\
\text { study }\end{array}$ \\
\hline RIB40 $\Delta p y r G:: G F P$ & $\begin{array}{l}\text { The auxotrophic RIB } 40 \triangle p y r G \text { strain transformed with pEX } 2 \mathrm{~B} \text { carrying } \\
\text { the pyrG marker and the GFP reporter gene under control of the } \\
\text { inducible amyB promoter }\end{array}$ & $\begin{array}{l}\text { This } \\
\text { study }\end{array}$ \\
\hline E. coli DH5a & E. coli expression host & $\begin{array}{l}\text { This } \\
\text { lab }\end{array}$ \\
\hline \multicolumn{3}{|l|}{ plasmids } \\
\hline pBC-Hygro & Filamentous fungal expression vector; $\mathrm{Hyg}^{\mathrm{R}}$ & $\begin{array}{l}\text { This } \\
\text { lab }\end{array}$ \\
\hline pHBT-GFP-NOS & pHBT carrying gfp gene & $\begin{array}{l}\text { This } \\
\text { lab }\end{array}$ \\
\hline pBC-Hygro1.0 & Hygromycin antibiotic gene deleted in pBC-Hygro & $\begin{array}{l}\text { This } \\
\text { study }\end{array}$ \\
\hline \multirow[t]{2}{*}{ pBC-Hygro4.0 } & pBC-Hygro1.0 + pyrG marker + GFP reporter gene & \multirow{2}{*}{$\begin{array}{l}\text { This } \\
\text { study }\end{array}$} \\
\hline & + His-tag + Promoter amyB + Terminator amyBt & \\
\hline
\end{tabular}




\section{Media And Culture Conditions}

The A. oryzae wild strain RIB40 was cultivated on Czapek-Dox (CD) medium ( $2 \%$ sucrose, $0.3 \% \mathrm{NaNO}_{3}$, $0.1 \% \mathrm{KH}_{2} \mathrm{PO}_{4}, 0.05 \% \mathrm{MgSO}_{4} \bigcirc 7 \mathrm{H}_{2} \mathrm{O}, 0.2 \% \mathrm{KCl}, 0.05 \% \mathrm{NaCl}, 0.002 \% \mathrm{FeSO}_{4} \bigcirc 7 \mathrm{H}_{2} \mathrm{O}, 2.0 \%$ agar, pH5.5). 5fluoroorotic acid (5-FOA) medium containing $0.6 \% \mathrm{NaNO}_{3}, 0.05 \% \mathrm{KCl}, 0.08 \% \mathrm{KH}_{2} \mathrm{PO}_{4}, 0.104 \% \mathrm{~K}_{2} \mathrm{HPO}_{4}$, $0.05 \% \mathrm{MgSO}_{4}-7 \mathrm{H}_{2} \mathrm{O}, 1 \%$ glucose, $0.122 \%$ uridine $2.0 \%$ agar, $0.5-1.5 \mathrm{mg} / \mathrm{mL} 5-\mathrm{FOA}$. CD + Uri/Ura medium containing $0.5 \%$ uridine and $0.2 \%$ uracil was used for the selection of pyrG deletion mutants. CD $+5-\mathrm{FOA}+$ Uri/Ura medium containing $1 \mathrm{mg} / \mathrm{mL} 5-\mathrm{FOA}, 0.5 \%$ uridine and $0.2 \%$ uracil was used for the growth of pyrG mutants. E. coli DH5a was used for the construction, propagation, and amplification of hybrid plasmids.

\section{Spore Preparation And Determination Of 5-foa Minimum Use Concentration}

The wild-type A. oryzae RIB40 was grown on (CD) medium for 3-5 days until the spores are mature. Sterile distilled water was added to the culture plate and fungal spores were released from the mycelium by scraping the agar surface with a sterile glass spreader under a laminar flow hood. The resulting mixture was collected with a micropipette and filtered through 500 mesh nylon cloth before centrifugation at $4000 \mathrm{rpm}$ for $10 \mathrm{~min}$. The spore pellet was washed twice with sterile distilled water and resuspended in sterile distilled water to obtain the spore suspension. The spore concentration was examined using a thoma counting chamber and adjusted to $1.0 \times 10^{7}$ spores $/ \mathrm{ml}$ for fungal transformation. The prepared spore suspension was pipetted into $200 \mu \mathrm{L}$ of 5-FOA medium, which is containing 5-FOA at different concentrations, and allowed to stand for $4-6$ days at $28^{\circ} \mathrm{C}$ to observe the growth of $A$. oryzae.

\section{Screening and characterization of pyrG deletion mutants}

Pipette $3 \mathrm{~mL}$ of the $1.0 \times 10^{7}$ spores $/ \mathrm{ml}$ spore suspension prepared above into a Petri dish, place it under UV light ( $30 \mathrm{~W}$ ) and irradiated for 5 minutes. The prepared spore suspension was pipetted into $500 \mu \mathrm{L}$ of 5-FOA medium, the above plate was wrapped with tin foil and allowed to stand for 3 to 4 days at $28^{\circ} \mathrm{C}$. Mutant strains to resistant to $5-F O A$ were transferred simultaneously to the $C D, C D+$ Uri/Ura and $C D+$ Uri/Ura + 5-FOA $(1 \mathrm{mg} / \mathrm{mL})$ to examine their growth. The mutants, which were unable to grow on the CD minimal medium, but could grow normally on $C D+$ Uri/Ura as well as on $C D+$ Uri/Ura $+5-F O A$, were selected for single spore isolation. These mutant strains were tested for mitotic stability for five successive generations on $\mathrm{CD}+\mathrm{Uri} / \mathrm{Ura}+5$-FOA before re-growing on $\mathrm{CD}$ medium.

The wild-type strains and the uridine/uracil auxotrophic mutants were cultivated in CD medium or CD + Uri/Ura for 4 days, at $28^{\circ} \mathrm{C}$. The obtained mycelia were used for genomic DNA extraction, and the primer pyrGF/pyrGR were used for PCR screening of $p y r G$ deletion mutants. 


\section{Abbreviations}

PyrG

orotidine-5'-monophosphate decarboxylase

UV mutagenesis

Ultraviolet mutagenesis

GFP

Green Fluorescent Protein

PMPT

polyethylene glycol-mediated protoplast transformation

ATMT

Agrobacterium tumefaciens-mediated transformation

FDA

Food and Drug Administration

OMP

orotidine-5'-monophosphate

5 -FOA

5-fluoroorotic acid

PDA medium

potato dextrose agar medium

Uri/Ura

uridine/uracil

$\mathrm{CD}$ medium

Czapek-Dox (CD) medium

\section{Declarations}

\section{Acknowledgements}

Not applicable.

\section{Author Contributions}

- Caixia Zhou performed the experiments, authored or reviewed drafts of the paper.

- Yujun Wan and Huipeng Yao performed the experiments.

- Hui Chen authored or reviewed drafts of the paper.

- Zizhong Tang conceived and designed the experiments, approved the final draft.

- Yirong Xiao and Zhi Shan analyzed the data.

- Tongliang Bu and Hong Chen prepared the figures and/or tables.

- Gang Wang contributed reagents/materials/analysis tools. 


\section{Funding}

We gratefully acknowledge financial support for this work from the Scientific Research Fundation of the Education Department of Sichuan Province, China(Grant No. 18ZB0455).

\section{Availability of data and materials}

All data generated or analyzed during this study are included in this published article and its additional files.

\section{Ethics approval and consent to participation}

Not applicable.

\section{Consent for publication}

Not applicable.

\section{Competing interests}

The authors declare no conflicts of interest.

\section{References}

1. Nguyen KT, Ho QN, Do LT, et al. A new and efficient approach for construction of uridine/uracil auxotrophic mutants in the filamentous fungus Aspergillus oryzae using Agrobacterium tumefaciens-mediated transformation. World J Microb Biot. 2017;33:107.

2. Nakamura $\mathrm{H}$, Katayama $\mathrm{T}, \mathrm{Okabe} \mathrm{T}$, et al. Highly efficient gene targeting in Aspergillus oryzae industrial strains under ligD mutation introduced by genome editing: Strain-specific differences in the effects of deleting EcdR, the negative regulator of sclerotia formation. J Gen Appl Microbiol. 2017;63:172-8.

3. Kitamoto K. Molecular biology of the Koji molds. Adv Appl Microbiol. 2002;51:129-54.

4. Kobayashi T, Abe K, Asai K, et al. Genomics of Aspergillus oryzae. Biosci Biotech Bioch. 2007;71:646-70.

5. Abe K, Gomi K, Hasegawa F, et al. Impact of Aspergillus oryzae genomics on industrial production of metabolites. Mycopathologia. 2006;162:143.

6. Lubertozzi D, Keasling JD. Developing Aspergillus as a host for heterologous expression. Biotechnol Adv. 2009;27:53-75.

7. Meyer V. Genetic engineering of filamentous fungi-progress, obstacles and future trends. Biotechnol Adv. 2008;26:177-85.

8. Meyer V, Wu B, Ram AF. Aspergillus as a multi-purpose cell factory: current status and perspectives. Biotechnol Lett. 2011;33:469-76. 
9. Suzuki S, Tada S, Fukuoka M, et al. A novel transformation system using a bleomycin resistance marker with chemosensitizers for Aspergillus oryzae. Biochem Bioph Res Co. 2009;383:42-7.

10. Woloshuk CP, Seip ER, Payne GA, et al. Genetic transformation system for the aflatoxin-producing fungus Aspergillus flavus. Appl Environ Microb. 1989;55:86-90.

11. Hirashima K, Iwaki T, Takegawa K, et al. A simple and effective chromosome modification method for large-scale deletion of genome sequences and identification of essential genes in fission yeast. Nucleic Acids Res. 2006;34:e11-1.

12. Kaneko S, Tanaka T, Noda $\mathrm{H}$, et al. Marker-disruptive gene integration and URA3 recycling for multiple gene manipulation in Saccharomyces cerevisiae. Appl Microbiol Biot. 2009;83:783-9.

13. Nielsen ML, Albertsen L, Lettier G, et al. Efficient PCR-based gene targeting with a recyclable marker for Aspergillus nidulans. Fungal Genet Biol. 2006;43:54-64.

14. Mattern IE, Unkles SE, Kinghorn JR, et al. Transformation of Aspergillus oryzae using the A. niger pyrG gene. Mol Gen Genet. 1987;210:460-1.

15. Hao L, Wang T, Zhang Y. Isolation of Trichoderma reesei pyrG negative mutant by UV mutagenesis and its application in transformation. Chem Res Chinese U. 2008;24:565-9.

16. Silva R, Aguiar TQ, Domingues L. Blockage of the pyrimidine biosynthetic pathway affects riboflavin production in Ashbya gossypii. J Biotechnol. 2015;193:37-40.

17. Du Y, Xie G, Yang C, et al. Construction of brewing-wine Aspergillus oryzae pyrG-mutant by pyrG gene deletion and its application in homology transformation. Acta Bioch Bioph Sin. 2014;46:477-83.

18. Liu Z, Friesen TL. Polyethylene glycol (PEG)-mediated transformation in filamentous fungal pathogens. Methods Mol Biol. 2012;835:365-75.

19. Michielse CB, Hooykaas PJ, Den Hondel CA, et al. Agrobacterium-mediated transformation as a tool for functional genomics in fungi. Curr Genet. 2005;48:1-17.

20. Ward OP. Production of recombinant proteins by filamentous fungi. Biotechnol Adv. 2012;30:111939.

21. Fitzgerald A, Mudge AM, Gleave AP, et al. Agrobacterium and PEG-mediated transformation of the phytopathogen Venturia inaequalis. Mycol Res. 2003;107:803-10.

22. Ruiz-Díez B. Strategies for the transformation of filamentous fungi. J Appl Microbiol. 2002;92:18995.

23. Willger SD, Cornish EJ, Chung D, et al. Dsc orthologs are required for hypoxia adaptation, triazole drug responses, and fungal virulence in Aspergillus fumigatus. Eukaryot Cell. 2012;11:1557-67.

24. Schmitt EK, Eilinghoff B, Olliger R, et al. Development of molecular tools for the mulundocandin producer Aspergillus sydowii: DNA-mediated transformation and reporter gene expression. Appl Microbiol Biot. 2002;58:625-31.

25. Gangavaram LP, Mchunu NP, Ramakrishnan P, et al. Improved electroporation-mediated nonintegrative transformation of Thermomyces lanuginosus. J Microbiol Meth. 2009;77:159-64. 
26. Malagnac F, Lalucque $H$, Lepere $G$, et al. Two NADPH oxidase isoforms are required for sexual reproduction and ascospore germination in the filamentous fungus Podospora anserina. Fungal Genet Biol. 2004;41:982-97.

27. Sha Y, Zhang Y, Qiu Y, et al. Efficient Biosynthesis of Low-Molecular-Weight Poly-Y-glutamic Acid by Stable Overexpression of PgdS Hydrolase in Bacillus amyloliquefaciens NB. J Agr Food Chem. 2018;67:282-90.

28. Yin Y, Mao Y, Yin X, et al. Construction of a shuttle vector for heterologous expression of a novel fungal a-amylase gene in Aspergillus oryzae. J Microbiol Biotechn. 2015;25:988-98.

29. Maruyama Jl, Kitamoto K. Multiple gene disruptions by marker recycling with highly efficient genetargeting background ( $\Delta$ ligD) in Aspergillus oryzae. Biotechnol Lett. 2008;30:1811.

30. Uchima C, Tokuda G, Watanabe H, et al. Heterologous expression and characterization of a glucosestimulated $\beta$-glucosidase from the termite Neotermes koshunensis in Aspergillus oryzae. Appl Microbiol Biot. 2011;89:1761-71.

31. Segato F, Damasio AR, Goncalves TA, et al. High-yield secretion of multiple client proteins in Aspergillus. Enzyme Microb Tech. 2012;51:100-6.

32. Kanamasa S, Yamaoka K, Kawaguchi T, et al. Transformation of Aspergillus aculeatus using the drug resistance gene of Aspergillus oryzae and the pyrG gene of Aspergillus nidulans. Biosci Biotech Bioch. 2003;67:2661-3.

33. Monod M, Paris S, Sarfati J, et al. Virulence of alkaline protease-deficient mutants of Aspergillus fumigatus. Fems Microbiol Lett. 1993;106:39-46.

34. Smith JM, Tang CM, Van Noorden S, et al. Virulence of Aspergillus fumigatus double mutants lacking restriction and an alkaline protease in a low-dose model of invasive pulmonary aspergillosis. Infect Immun. 1994;62:5247-54.

35. d'Enfert C. Selection of multiple disruption events in Aspergillus fumigatus using the orotidine-5'decarboxylase gene, $p y r G$, as a unique transformation marker. Curr Genet. 1996;30:76-82.

36. Ling So, Storms R, Zheng Y, et al. Development of a pyrG mutant of Aspergillus oryzae strain S1 as a host for the production of heterologous proteins. The Scientific World J. 2013; 2013:634317634317.

37. Gouka RJ, Punt PJ, Van Den Hondel CAMJJ. Efficient production of secreted proteins by Aspergillus. progress, limitations and prospects. Appl Microbiol Biot. 1997;47:1-11.

38. Ishida $\mathrm{H}$, Matsumura $\mathrm{K}$, Hata $\mathrm{Y}$, et al. Establishment of a hyper-protein production system in submerged Aspergillus oryzae culture under tyrosinase-encoding gene (me/O) promoter control. Appl Microbiol Biot. 2001;57:131-7.

39. Kitamoto N, Matsui J, Kawai Y, et al. Utilization of the TEF1-a gene (TEF1) promoter for expression of polygalacturonase genes, pgaA and pgaB, in Aspergillus oryzae. Appl Microbiol Biot. 1998;50:85-92.

40. Lubertozzi D, Keasling JD. Developing Aspergillus as a host for heterologous expression. Biotechnol Adv. 2009;27:53-75. 
41. Nemoto T, Maruyama JI, Kitamoto K. Contribution ratios of amyA, amyB, amyC genes to high-level aamylase expression in Aspergillus oryzae. Biosci Biotech Bioch. 2012; 76:1477-1483.

42. Nguyen KT, Ho QN, Pham TH, et al. The construction and use of versatile binary vectors carrying pyrG auxotrophic marker and fluorescent reporter genes for Agrobacterium-mediated transformation of Aspergillus oryzae. World J Microb Biot. 2016;32:204.

43. Lorang JM, Tuori RP, Martinez JP, et al. Green fluorescent protein is lighting up fungal biology. Appl Environ Microb. 2001;67:1987-94.

44. Tada S, limura Y, Gomi K, et al. Cloning and nucleotide sequence of the genomic Taka-amylase $A$ gene of Aspergillus oryzae. Agric Biol Chem. 1989;53:593-9.

45. Hata Y, Katsuhiko K, Gomi K, et al. The glucoamylase cDNA from Aspergillus oryzae: its cloning, nucleotide sequence, and expression in Saccharomyces cerevisiae. Agric Biol Chem. 1991;55:941-9.

46. Yoji $\mathrm{H}, \mathrm{Kozo} \mathrm{T}$, Katsuhiko $\mathrm{K}$, et al. Nucleotide sequence and expression of the glucoamylase-encoding gene ( $g / a A)$ from Aspergillus oryzae. Gene. 1991;108:145-50.

47. Minetoki T, Gomi K, Kitamoto K, et al. Nucleotide sequence and expression of a-glucosidase-encoding gene (agdA) from Aspergillus oryzae. Biosci Biotech Bioch. 1995;59:1516-21.

48. Unkles SE, Campbell El, De Ruiterjacobs YM, et al. The development of a homologous transformation system for Aspergillus oryzae based on the nitrate assimilation pathway: a convenient and general selection system for filamentous fungal transformation. Mol Gen Genet. 1989;218:99-104.

\section{Figures}

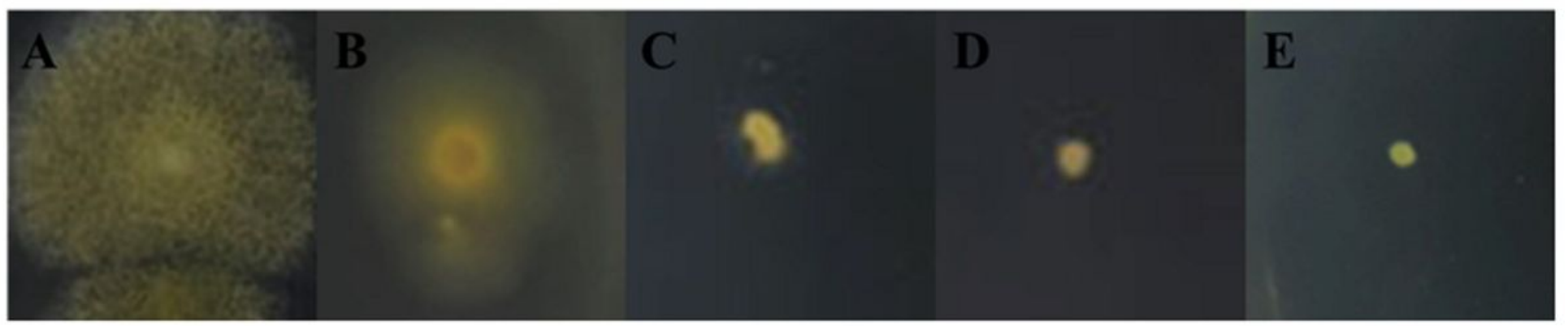

\section{Figure 1}

Effects of 5-FOA on the growth of A. oryzae RIB40 A-E: Growth of A. oryzae RIB40 in $0.5,0.75,1.0,1.25$, $1.5 \mathrm{mg} / \mathrm{mL} 5$-FOA plates 


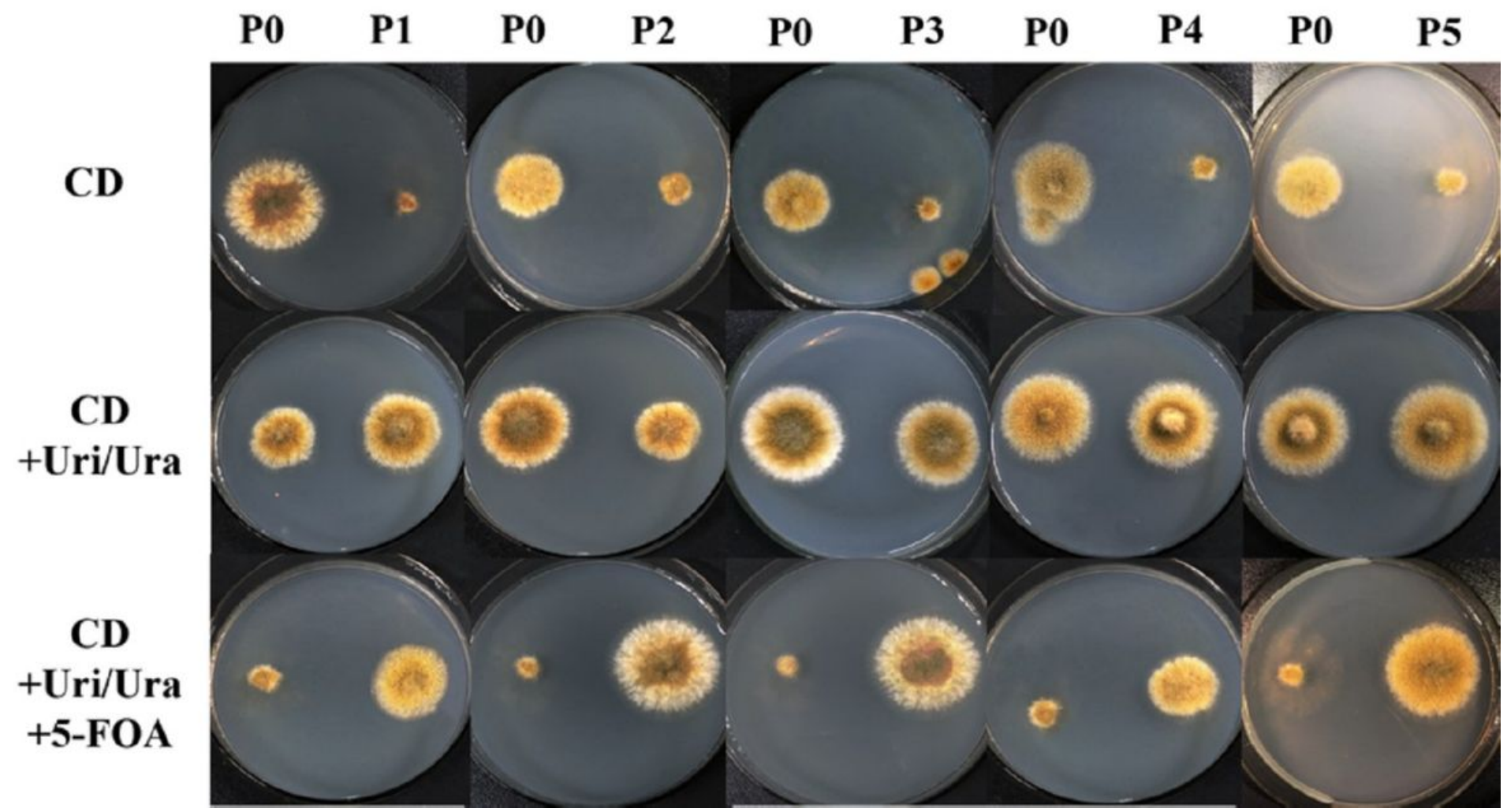

Figure 2

Characterization of pyrG deletion mutants generated from the A. oryzae RIB40 strain P0: wild type RIB40; P1-P5: the pyrG deletion strains.
$\mathrm{M}$
$\mathrm{P} 1$
$\mathrm{P} 2$
$\mathrm{P} 3$
$\mathrm{P} 4$
P5

$4500 \mathrm{bp}$ $3000 \mathrm{bp}=$ $2000 \mathrm{bp}$ $1200 \mathrm{bp}$ 800 bp 500 bp

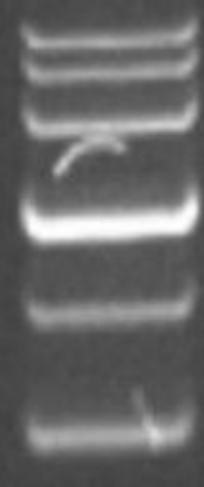

$200 \mathrm{bp}$ 
Figure 3

The pyrG deletion mutants was confirmed by PCR M: Marker III; P1-P5: pyrG mutant strains po.txt ACCGGTCAATATACTACTTCTTCTGTTGACTATGCTCGGA pl.txt ACCGGTCAATATACTACTTCTTCTGTTGACTATGCTCGGA

Consensusaccggtcaatatactacttctctgttgactatgctcgga

po.txt AGTATAA AAGTTTGTGATGGATTCGTC.TCGACACGTC
pl.txt AGTATAA.AAGTTTGTGATGGGATCGTCICGACACGTC

Consensusagtataa aagtttgtgatgggattcgtc tcgacacgtc

po.txt ACCTTGGCGAGGTTCAGTCTGAAGTTAGCTCGCCTTCGGA pl.txt ACCTTGGCGAGGTTCAGTCTGAAGTTAGCTCGCCTTCGGA

Consensusacctiggcgaggttcagtctgaagttagctcgecttcgga

po.txt GGAGGAAGATTTGTCGTCTTCACGACAGGTGTCAACCTC
pl.txt GGAGGAAGATTTGTCGTCTTCACGACAGGTGTCAACCTC

Consensusggaggaagattttgtcgtcttcacgacaggtgtcaacctc

\section{Figure 4}

pyrG sequence comparison RIB40 and mutant strain p0: RIB40; p1: mutant strain 
A

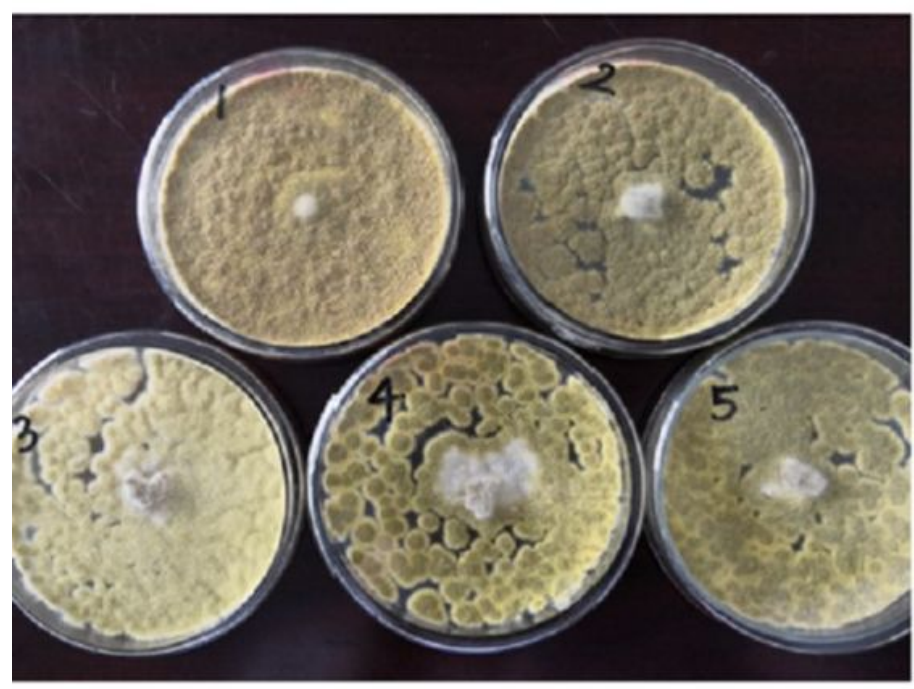

B

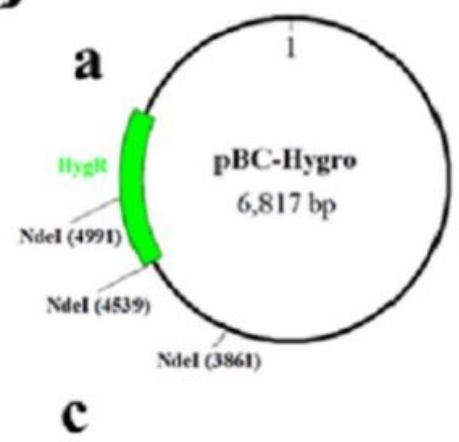

Ndel (3861)

CATATG--.---TATATG
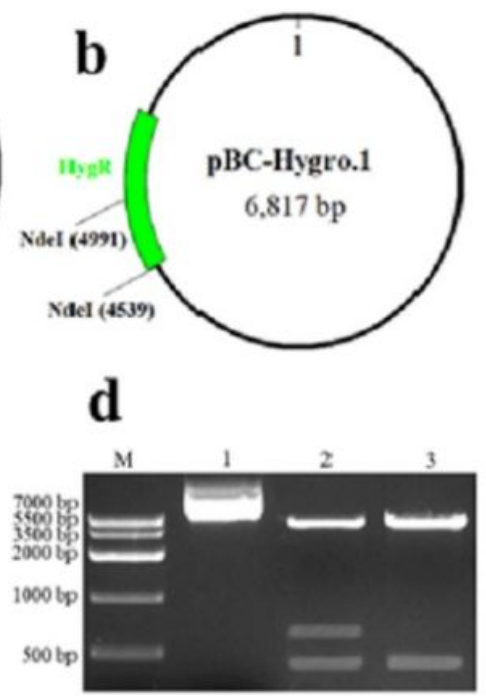

Figure 5

Inhibition hygromycin B on growth of RIB40 $\triangle$ pyrG 1-5: The growth of RIB40 $\triangle \mathrm{pyrG}$ on the MM plate containing hygromycin $B$ containing $0,0.5 \mathrm{mg} / \mathrm{mL}, 1.0 \mathrm{mg} / \mathrm{mL}, 1.5 \mathrm{mg} / \mathrm{mL}, 2.0 \mathrm{mg} / \mathrm{mL}$ respectively. Fig. 5B The scheme for destroying hygromycin sequences of plasmid pBC-Hygro A: Mapping of pBC-Hygro plasmid marking Nde I locus; B: Mapping of pBC-Hygro mutant plasmid marking Nde I locus; C: Mutation 3861 restriction site. The box and underling indicate deleted nucleotides mutation sites; D: Verification of mutant plasmid pBC-Hygro.1 by Nde I. M, DNA Marker IV; 1, plasmid pBC-Hygro; 2, plasmid pBC-Hygro by Nde I digestion; 3, mutant plasmid pBC-Hygro. 1 by Nde I digestion. 
pBC-Hygro.txt

pBC-Hygro.1.txt

Consensus

pBC-Hygro.txt

pBC-Hygro.1.txt

Consensus

pBC-Hygro.txt

pBC-Hygro.1.txt

Consensus

pBC-Hygro.txt

pBC-Hygro.1.txt

Consensus

pBC-Hygro.txt

pBC-Hygro.1.txt

Consensus
GGGGCTGACTGCCTCAGGTGGGGCAGTGCTAGTGTGTGTA

GGGGCTGACTGCCTCAGGTGGGGCAGTGCTAGTGTGTGTA

ggggctgactgcctcaggtggggcagtgctagtgtgtgta

CCGACCCGCAGGATTGGTGCTTTGCCCAGAGCTCTACAGA

CCGACCCGCAGGATTGGTGCTTTGCCCAGAGCTCTACAGA

200

ccgacccgcaggattggtgctttgcccagagctctacaga

ATAGCGCGCGCATCATATGTTAGTTCTGCAATTTTCTTG

ATAGCGCGCGCATCIATATGTIAGTTCTGCAATTTCTTG

atagcgcgcgcatc atatgttagttctgcaattttcttg

TATCGGTGCTGTGACTCATACTTCCCCCTTTGGCTGGCCT

TATCGGTGCTGTGACTCATACTTCCCCCTTTGGCTGGCCT

280

280

tatcggtgctgtgactcatacttccectttggetggcet

TGCGGCAACCAATAAGAACGCACAGTGAAATCTTGCGGGT

TGCGGCAACCAATAAGAACGCACAGTGAAATCTTGCGGGT

320

tgcggcaaccaataagaacgcacagtgaatcttgcgggt

Figure 6

Partial sequence alignment of plasmids pBC-Hygro and pBC-Hygro.1

A

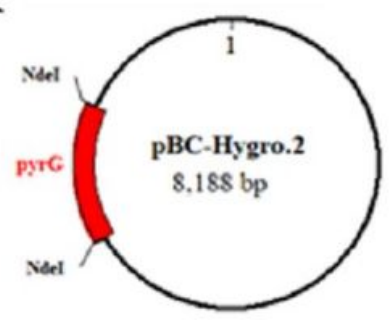

C

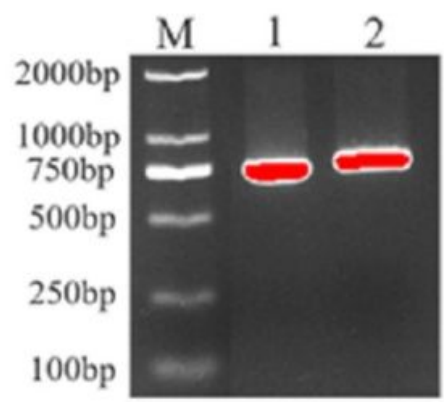

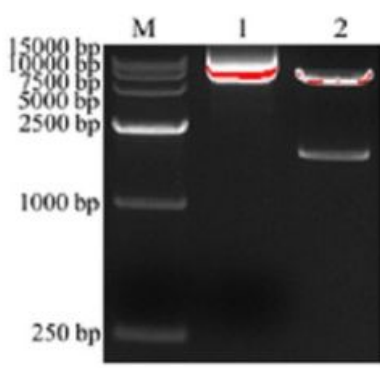

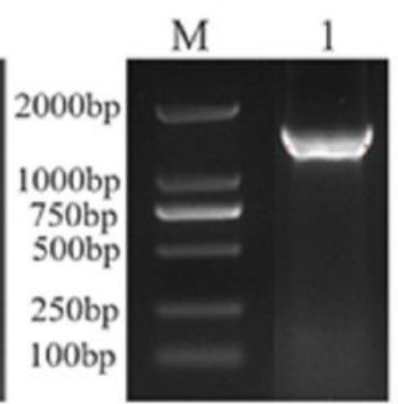

B

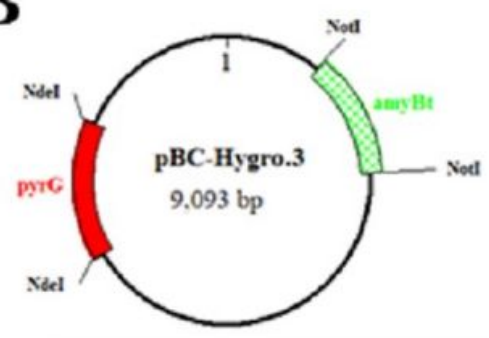

D

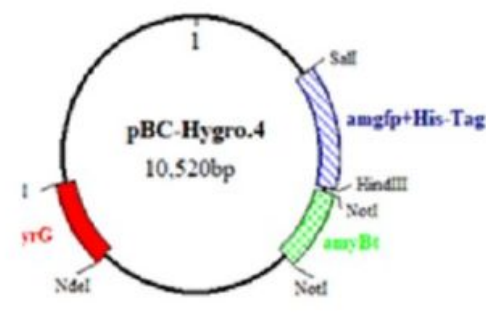

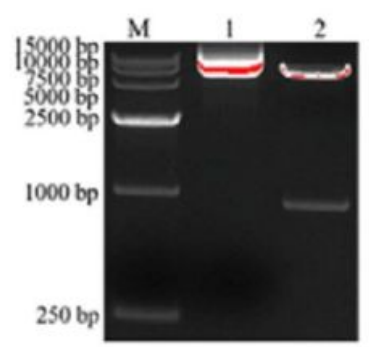

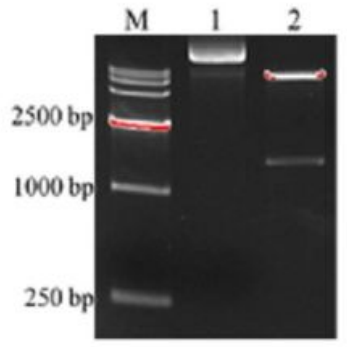

Figure 7

Schematic illustration of pBC-hygro, and binary expression vectors pBC-hygro.2, pBC-hygro.3, and pBChygro.4 A: pBC-hygro. 2 was constructed using a pBC-hygro backbone, containing a pyrG gene expression 
cassette; $\mathrm{B}$ : pBC-hygro.3 was generated by insertion of amyB ( $A$. oryzae amyB terminator); C: Fusion of target genes amyB ( A. oryzae amyB promoter) and GFP by fusion PCR(M: DNA Maker DL2000; 1, amyB; 2, GFP; M: DNA Maker DL2000; 1, fusion gene amgfp)Lanes from left to right; D: pBC-hygro.4 was generated by insertion of the fusion gene amgfp.

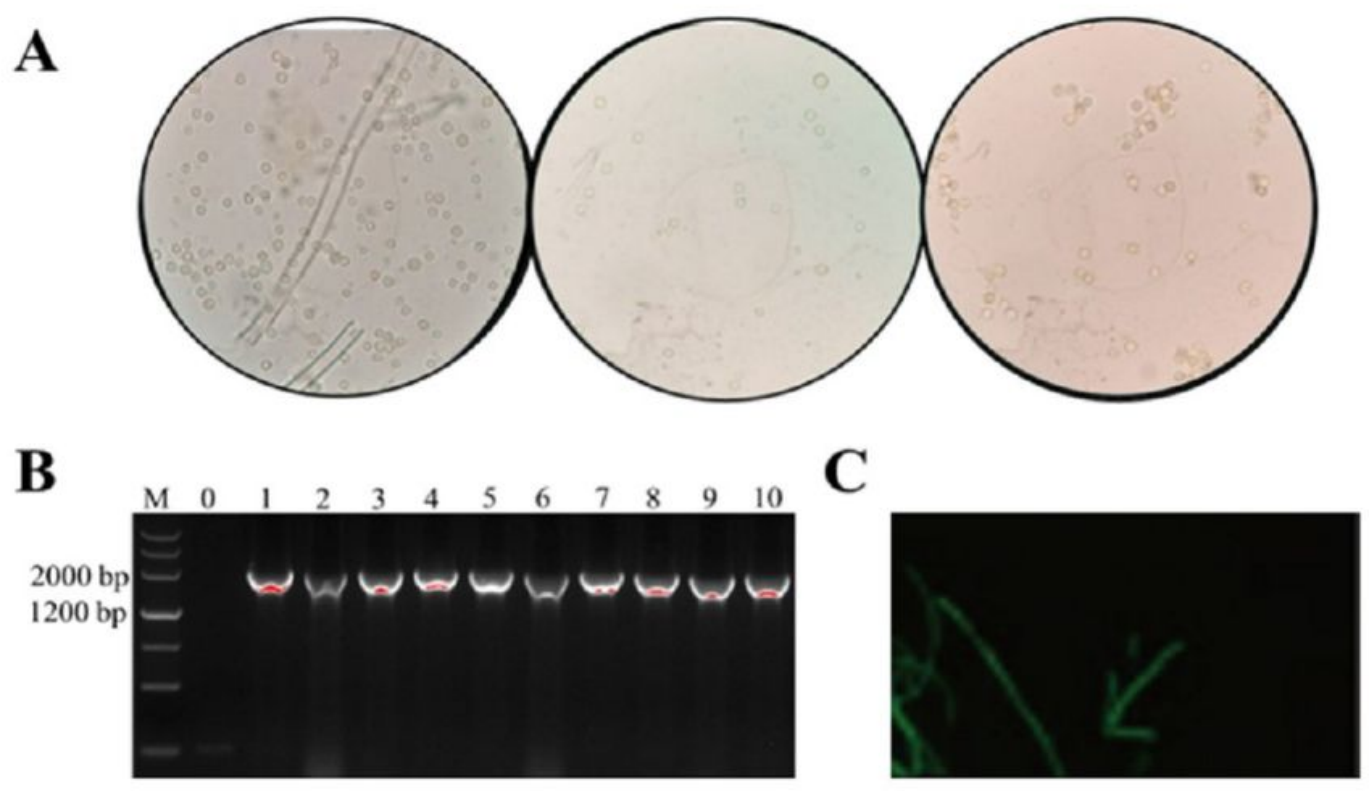

\section{Figure 8}

Verification of Aspergillus oryzae expression vector A: From left to right, protoplast enzymatic hydrolysis for $2 \mathrm{~h}, 3 \mathrm{~h}$, and $4 \mathrm{~h}$; B: Verification of transformant colony by PCR; M: DL2000, 0: negative control, 1-10: transformant colonies; C: Observation of GFP expression by fluorescence microscopy 